\title{
Nanocomposites based on chain extended poly(L-lactic acid)/carboxylated carbon nanotubes: Crystallization kinetics and lamellar morphology
}

(C) The Author(s) 2019

Article reuse guidelines: sagepub.com/journals-permissions DOI: I0.1 I77/002 | 9983 |8822720 journals.sagepub.com/home/jcm

SAGE

\author{
Omid Yousefzade' $\odot$, Lourdes Franco², Mahsa Nami', \\ Jordi Puiggali ${ }^{2}$ and Hamid Garmabi
}

\begin{abstract}
Isothermal and nonisothermal crystallization kinetics of poly(L-lactide) and its nanocomposites with different multiwalled carbon nanotubes (i.e., pristine and functionalized) were investigated. The effects of chain extension and nanofiller content on the crystallization kinetics were also explored. The Avrami analysis was applied as a useful tool for the study of isothermal crystallization kinetics, which was also supported by optical microscopy observations. In addition, in nonisothermal crystallization process, the Avrami and Mo methodologies were used to study the crystallization kinetics as well as the evaluation of activation energy from isoconversional methods. The activation energy was always negative for the process driven by the secondary nucleation. Great differences were found between the studied samples, but activation energy values indicated a favored crystallization (i.e., less negative energies) when functionalized multiwalled carbon nanotubes were added at a concentration of $0.2 \mathrm{wt} \%$. Cold crystallization was also influenced by the multiwalled carbon nanotube content due to the nucleating effect and the existence of geometrical constrictions that limited the size of crystalline domains. Small-angle X-ray scattering studies showed that the size of crystal lamellae after cold crystallization could vary by a magnitude of $3 \mathrm{~nm}$ depending on the way as the sample was previously cooled (i.e., by the presence of incipient crystalline domains).
\end{abstract}

\author{
Keywords \\ Crystallization kinetics, polylactide, carbon nanotubes, chain extension
}

\section{Introduction}

Studies on poly(L-lactide) (PLLA) are nowadays exponentially growing due to the performance of this polymer in various fields such as biomedical and packaging industries. ${ }^{1-3}$ PLLA can be found either in both completely amorphous or semi-crystalline forms, depending on its chemical structure (i.e., the enantiomeric content) and the processing conditions. ${ }^{4-7}$ In addition, physicochemical characteristics of PLLA deserve deeper studies according to a more fundamental/basic point of view. It is well known that PLLA slowly crystallizes from the melt state, which allows preparing materials with tuned degrees of crystallinity and different lamellar morphologies by changing the thermal history. ${ }^{8-10}$ Furthermore, cold crystallization becomes a fundamental process that allows modulating physical properties through subsequent thermal treatments. Different techniques, such as atomic force microscopy, ${ }^{11}$ transmission electronic microscopy, ${ }^{12}$ optical microscopy, ${ }^{13}$ smalland wide-angle X-ray scattering/diffraction (SAXS and WAXD) ${ }^{14}$ and differential scanning calorimetry

\footnotetext{
'Department of Polymer Engineering and Color Technology, Amirkabir University of Technology, Iran

${ }^{2}$ Chemical Engineering Department, Escola d'Enginyeria de Barcelona Est-EEBE, Spain

\section{Corresponding authors:}

Jordi Puiggali, Chemical Engineering Department, Escola d Enginyeria de Barcelona Est-EEBE, Spain.

Email: jordi.puiggali@upc.edu

Hamid Garmabi, Department of Polymer Engineering and Color

Technology, Amirkabir University of Technology, Iran.

Email: garmabi@aut.ac.ir
} 
(DSC) ${ }^{15-17}$ were used to explore crystallization kinetics, structure, and morphologies of polymer crystals.

The inherent difficulty of PLLA to crystallize as consequence among other factors of the high stiffness of molecular chains are the reasons to focus on crystallization process using two different additives: (1) incorporation of nucleating agents such as nanoparticles to enhance the crystallization process, ${ }^{18}$ (2) incorporation of additives with a plasticizing effect to decrease the glass transition temperature of the amorphous phase and the rigidity of the material. ${ }^{19,20}$ Recent research results have shown that applying the chain branching (i.e., connecting the terminal groups through a multifunctional chain extender) is an effective way to improve PLA processability as well as physical and mechanical properties. ${ }^{21}$ It was found that chain extension of PLLA influenced the kinetics of both isothermal and nonisothermal crystallization. ${ }^{7,22}$

Multiwalled carbon nanotubes (MWCNTs) attract more attention among nanoparticles due to their high efficiency as nucleating agents and their ability to control both the degree of crystallinity and the crystallization kinetics. ${ }^{23-25}$ The effect derived from the presence of MWCNT in the increase of nucleation has been extensively reported, but the detailed understanding of the role of MWCNT in the growth of polymer crystals remains a complex topic. It is generally believed that MWCNTs lead to a heterogeneous nucleation, which is typically much faster than the neat polymer. $^{26,27}$ The effect of MWCNTs on polymer crystallization is similar to that of classical nucleation agents, which leads to an increase in crystallization temperatures, enhancement in nucleation density, and reduction of crystallization times. ${ }^{28}$ In addition, CNTs interactions with the semicrystalline polymer may potentially alter the crystallization kinetics and the crystalline morphology. ${ }^{29} \mathrm{Hu}$ et al. ${ }^{24}$ studied the mechanism of PLLA crystallization induced by MWCNTs using Fourier transform infrared spectroscopy (FTIR). They found that MWCNTs provided templates for the conformational ordering of PLLA by interaction of PLLA chains with MWCNT surfaces. This physical and/or chemical interaction resulted in $-(\mathrm{COC}+$ $\mathrm{CH}_{3}$ ) conformational changes that preceded equivalent changes of $-\mathrm{CH}_{3}$ counterparts. Their work showed that it takes less time for pure PLLA and PLLA/pristine MWCNTs to complete crystallization than with carboxylated MWCNTs. Shie et al ${ }^{30}$ studied the effect of CNT grafted by PLA on crystal structure of PLLA by WAXS and SAXS. It was reported that both the thickness of crystal lamellae and amorphous layer thicknesses decreased after cold crystallization by addition of a sufficient concentration of functionalized MWCNTs (i.e., $2 \mathrm{wt} \%$ of MWCNTs). Recently, Chen et al. ${ }^{25,31}$ investigated the effect CNTs on the crystallization kinetics of PLLA and the generation of a transcrystalline structure around the nanotubes. This transcrystalline structure caused an increase of the crystallization temperature and improved the thermal stability of linear PLLA.

The present study focuses on the effects caused in the crystallization by the incorporation of small amounts of functionalized and pristine MWCNTs, considering also their potential participation in chain extension processes that lead to PLLA samples with increased molecular weight. Recently, a multifunctional styrene-acrylicepoxy random oligomer $\left(\right.$ Joncryl $^{\circledR}$ ) has been proposed as chain-extension agent for PLA during reactive extrusion. ${ }^{32,33}$ This type of chain extension process provides nonlinear polymer chains without crosslinked polymer chains. Al-Itry et al. ${ }^{34}$ showed an improvement of the thermal stability of PLA through reactive extrusion of PLA with various amounts of multifunctional epoxide leading to an enhancement of the viscoelastic and mechanical properties. Cailloux et al. ${ }^{35}$ suggested a competition between degradation, chain extension as well as branching reactions during processing with the incorporation of a styrene-acrylic multifunctional oligomeric agent on the PLA matrix. The present work deals about the isothermal and nonisothermal crystallization kinetics and the derived crystalline morphologies of this type of chain extended PLLA in the presence of MWCNTs. This topic has scarcely been studied to the best of our knowledge despite it deserves great interests due to the increasing attention received by multifunctional chain extension and obviously by the incorporation of MWCNTs. In addition to the obvious changes produced by the presence of nanoparticles in the derived spherulitic morphologies, special attention will be paid to the different lamellar sizes that can be developed in samples submitted to different thermal histories during the previous cooling from the melt.

\section{Experimental section}

\section{Materials}

Poly (L-lactide) (PLLA), grade 4032D, was purchased from Natureworks LLC, USA. It is a semi-crystalline material containing $2 \%$ of D-lactide units. MWCNTs (with average diameter, length, and specific surface area of $9.5 \mathrm{~nm}, 1.5 \mu \mathrm{m}$, and $250-300 \mathrm{~m}^{2} / \mathrm{g}$, respectively) was provided by Nanocyl (Nanocyl7000 series, Belgium). Commercial multifunctional styrene-acrylic oligomers (BASF, Joncryl ${ }^{\circledR}$ ADR-4368) were used as a reactive agent. The sample is supplied in flake form and has the following physical characteristics according to the manufacturer: $\mathrm{M}_{\mathrm{n}}<3000$, epoxy functions $(\mathrm{fn})>4$, PDI $>3$, epoxy equivalent weight $(E E W)=285 \mathrm{~g} / \mathrm{mol}$, and $\mathrm{T}_{\mathrm{g}}=55^{\circ} \mathrm{C}$. 


\section{Sample preparation}

Carboxylated MWCNTs were prepared through an acid oxidation process developed in a previous work. ${ }^{36}$ This functionalization allowed achieving a good dispersion of MWCNTs in the PLLA matrix. The amount of carboxyl groups in f-CNTs was found $7.1 \mathrm{wt} \%$ by comparing the thermogravimetric (TGA) curves (in the $100^{\circ} \mathrm{C}-500^{\circ} \mathrm{C}$ range) of p-CNT and $\mathrm{f}$-CNT. The mass loss at temperatures below $500^{\circ} \mathrm{C}$, which corresponds to the degradation of carboxyl groups, offers a direct evidence for the acid oxidization degree. ${ }^{37}$ It should be pointed out that the content could be slightly overestimated due to the presence of a minor amount of other organic matter.

PLLA/MWCNTs master batch with $5 \mathrm{wt} \%$ of MWCNTs was prepared by solvent casting using chloroform as solvent. In order to get nanocomposites with different MWCNT loadings and polymer molecular weights, the obtained masterbatch was melt compounded with the appropriate amounts of PLLA in the presence or absence of the selected chain modifier (i.e., Joncryl ${ }^{\circledR}$ ADR) for reactive and nonreactive melt mixing, respectively. A lab-scale internal mixer (Brabender mixer, PL2200) operating at $190^{\circ} \mathrm{C}$ and $60 \mathrm{r} / \mathrm{min}$ was used. Chain extender reactions were considered completed when a plateau in torque curves was achieved. This time was $15 \mathrm{~min}$ for the longest case and therefore was applied for all studied samples, including those prepared without Joncryl ${ }^{\circledR}$. The amount of chain modifier was set to $0.5 \mathrm{wt} \%$ for all samples prepared via reactive melt mixing since it corresponds to a default of epoxy groups with respect the total content of carboxylic groups (i.e., from the polymer and the MWCNTs). In this way, all epoxy groups can be consumed during the chain extension reaction and the risk of having crosslinking reactions minimized. Dispersion state of MWCNTs in the PLLA and the effect of chain extension process on molecular weight and structure of PLLA were discussed in our previous works. ${ }^{36,38}$

The studied samples are named by the abbreviation PLLA/x-CNTy/Z. The lower case before CNT indicates pristine (p) or functionalized (f) fillers and the number after CNT shows its weight fraction in the nanocomposite. The upper case at the end of the code indicates reactive $(\mathrm{R})$ or nonreactive $(\mathrm{N})$ melt mixing, for example, PLLA $/ \mathrm{f}-\mathrm{CNT} 0.2 / \mathrm{N}$ corresponds to the nanocomposite containing $0.2 \mathrm{wt} \%$ of functionalized MWCNTs prepared by nonreactive melt mixing, whereas PLLA/p-CNT0.2/R corresponds to the nanocomposite containing $0.2 \mathrm{wt} \%$ of pristine MWCNT during reactive melt mixing. Figure 1 summarizes the different studied samples and a possible chain extended structure where the styrene-acrylic multifunctional oligomeric chain is joined to both PLLA chains and
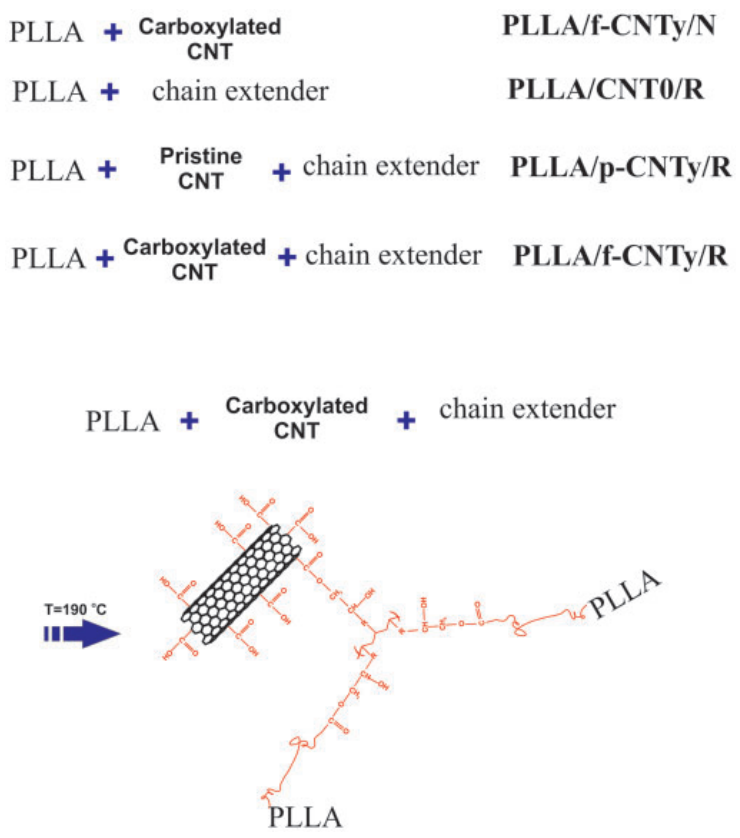

Figure I. Nomenclatures of samples, general structure of Joncryl ADR and scheme of a possible chain extension reaction in the presence of carboxylated MWCNTs. Where RI-R5 are H, $\mathrm{CH}_{3}$, a higher alkyl group, or combinations of them; $\mathrm{R} 6$ is an alkyl group, and $\mathrm{x}, \mathrm{y}$ and $\mathrm{z}$ are each between $\mathrm{I}$ and 20 .

MWCNTs. Thus, it can be hypothesized that the default epoxy groups of Joncryl can react in the melt state with the carboxylic groups of both polymer chains and nanotubes, giving rise to a certain ratio of this hybrid structure.

\section{Measurements}

Transmission electron microscopy (TEM, Philips TECNAI 10 operating at $80 \mathrm{kV}$ ) was used to evaluate the morphology and dispersion of MWCNTs in the prepared nanocomposites. Samples were cut in thin sections (i.e., $50-80 \mathrm{~nm}$ thick) using an ultramicrotome provided with a diamond knife.

Molecular weights and polydispersity index (PDI) were measured by gel permeation chromatograpy (GPC) using a liquid chromatograph (Shimadzu, model LC-8 A) equipped with an Empower computer program (Waters). A PL HFIP gel column (Polymer Lab $300 \mathrm{~mm} \times 7.5 \mathrm{~mm}$ ) and a refractive index detector (Shimadzu RID-10A) were employed. The polymer was dissolved and eluted in 1,1,1,3,3,3-hexafluoroisopropanol (HFIP) containing $\mathrm{CF}_{3} \mathrm{COONa}(0.05 \mathrm{M})$ at a flow rate of $0.5 \mathrm{~mL} / \mathrm{min}$ (injected volume $100 \mu \mathrm{L}$, approximate sample concentration $1.5 \mathrm{mg} / \mathrm{mL}$ ). The number and weight average molecular weights were calculated using poly(methyl methacrylate) standards. 
Melting and crystallization characteristics of samples were examined using a METTLER TOLEDO DSC1 system. Samples with $9 \mathrm{mg}$ weight were encapsulated in aluminum pans and treated at heating/cooling ramps in the range of $25^{\circ} \mathrm{C}-200^{\circ} \mathrm{C}$ with the heating rate of $10^{\circ} \mathrm{C} / \mathrm{min}$ and cooling rates of $2.5,5,7.5$, and $10^{\circ} \mathrm{C} / \mathrm{min}$. In addition, isothermal crystallization was performed for all samples at three different temperatures $\left(110^{\circ} \mathrm{C}, 120^{\circ} \mathrm{C}\right.$, and $\left.130^{\circ} \mathrm{C}\right)$. Samples were heated to $200^{\circ} \mathrm{C}$ and rapidly cooled to the selected isothermal crystallization temperature after erasing thermal history by keeping the sample in the melt state for 2 min. Crystallization process at the selected temperatures needed a maximum of $50 \mathrm{~min}$ to complete. The applied atmosphere was nitrogen with a flow rate of $50 \mathrm{~mL} / \mathrm{min}$.

Optical micrographs were taken with a Zeiss Axioskop 40 Pol light polarizing microscope equipped with a Zeiss AxiosCam MRC5 digital camera. Temperature was controlled with a Linkam system having a THMS 600 heating and freezing stage connected to an LNP 94 liquid nitrogen cooling system.

Combined SAXS and WAXD experiments were carried out in the noncrystalline diffraction beamline, BL-11, at ALBA synchrotron light source (www.albasynchrotron.es). Polymer samples were confined between Kapton films and then placed on a Linkam hot stage with temperature control within $\pm 0.1^{\circ} \mathrm{C}$. Diffraction profiles were acquired during heating $\left(10^{\circ} \mathrm{C} / \mathrm{min}\right)$ and cooling runs in time frames of $10 \mathrm{~s}$ and different cooling rates $(2.5,5,7.5$, and $10^{\circ} \mathrm{C} / \mathrm{min}$ )

The energy of the incident photons was $12.4 \mathrm{keV}$ or equivalently a wavelength, $\lambda$, of $0.1 \mathrm{~nm}$. The SAXS diffraction patterns were collected by means of a photon counting detector ImXPAD S1400 with an active area of $152 \times 149.6 \mathrm{~mm}^{2}$, an effective pixel size of $130 \times 130 \mu \mathrm{m}^{2}$ and a dynamic range of 32 bits. The sample-to-detector distance was set to $6163 \mathrm{~mm}$, resulting in a $q$ range with a maximum value of $q=2 \mathrm{~nm}^{-1}$.

Additionally, the WAXS diffraction patterns were collected by means of a 3 CCD detector Rayonix LX255-HS with an active area of $85 \times 255 \mathrm{~mm}^{2}$, an effective pixel size of $44 \times 44 \mu \mathrm{m}^{2}$ and a dynamic range of 16 bits. In this case, the sample-to-detector distance was set to $225 \mathrm{~mm}$, corresponding to a maximum $q$ value of $62 \mathrm{~nm}^{-1}$. This detector was tilted with a pitch of 29.8 degrees.

The data reduction was treated by pyFAI python code (ESRF), modified by ALBA beamline staff, that is able to do on-line azimuthal integrations from a previously calibrated file. The calibration files were created from well-known standards, that is, silver behenate $(\mathrm{AgBh})$ and $\mathrm{Cr}_{2} \mathrm{O}_{3}$ for SAXS and WAXS, respectively.

\section{Results and discussion}

\section{Morphology and molecular weight of nanocomposites}

Figure 2(a) shows the increase of molecular weight of samples after performing the chain extension process using Joncryl ${ }^{\mathbb{R}}$. Thus, weight average molecular weight increased from $180 \pm 20 \mathrm{~kg} / \mathrm{mol}$ to $400 \pm 30 \mathrm{~kg} /$ mol, being not detected a highly significant variation between the different nanocomposite preparations of a given series (i.e., with or without chain extender). Nevertheless, chain extension was slightly less effective for functionalized MWCNTs than for pristine samples due to the competitive reaction between carboxyl groups and the chain extender. Note, for example, that $M_{w}$ values of 428 and $358 \mathrm{~kg} / \mathrm{mol}$ were determined for PLLA/p-CNT0.2/R and PLLA/f-CNT0.2/R samples, respectively. Polydispersity index (PDI) of all samples clearly increased after the chain extension process as presumable from the presence of a fraction of longer molecules generated by chain extension. Note that the

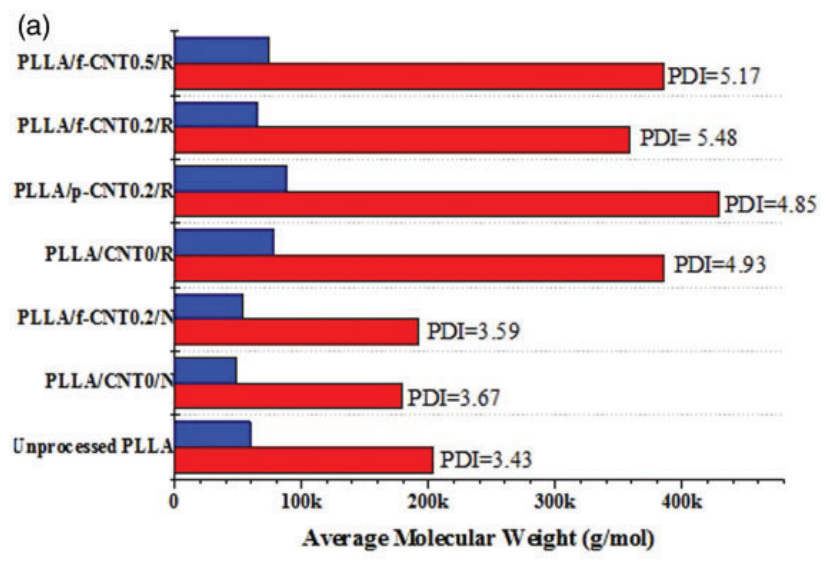

(b)

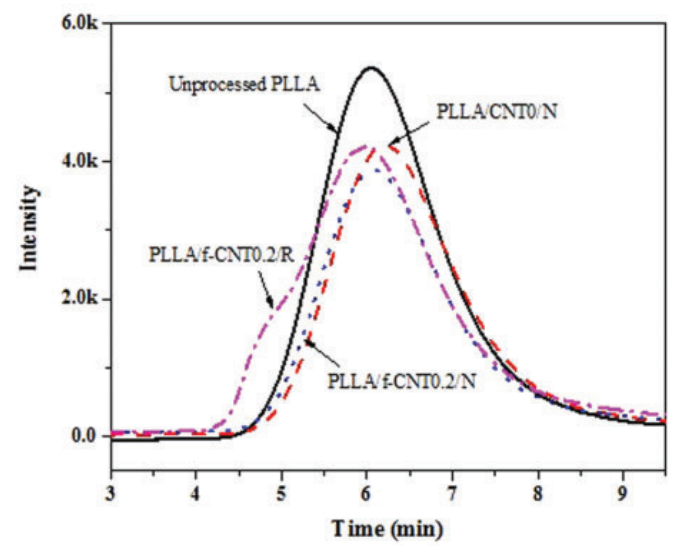

Figure 2. Number average (blue columns) and weight average (red columns) molecular weights of the studied samples (a) and representative GPC molecular weight distributions of PLLA and its nanocomposites (b). 
variation on the number average molecular weight was less significant since it is less affected by the presence of large molecules.

Representative GPC molecular weight distributions of PLLA and their nanocomposites are shown in Figure 2(b). It is clear the appearance of a shoulder in the spectrum of chain extended PLLA that corresponds to the longer molecules derived from the chain extension process. It is known that Joncryl chain extender can create star branch PLLA chains which elute from the GPC column sooner due to their bigger size.

MWCNT morphologies, aggregation state, and distribution inside the corresponding nanocomposite can be well distinguished in TEM micrographs as shown in Figure 3 for two representative samples. Differences between nanocomposites prepared from pristine and functionalized MWCNT samples (e.g., PLLA/pCNT0.2/N and PLLA/f-CNT0.2/R) are highly relevant. Thus, agglomeration is typical for pristine nanotubes (Figure 3(a)) while there are less aggregations using carboxylated CNT (Figure 3(b) and (c)). In other words, Since Joncryl has multiple reactive end groups, several PLA chains could be chemically bounded with one Joncryl molecule. In this way, a chain extended, branched or crosslinked structures and new bonding between PLA and carboxylated CNTs could be developed. It was also found that the degree of crosslinking (gel fraction) is less than $0.5 \%$ for all samples which is in good agreement with the study of Najafi et al. ${ }^{32}$

The improved dispersion is a clear indication that a good interaction between the functionalized MWCNTs and PLLA chains was achieved as schematically shown in Figure 1.

\section{Isothermal crystallization}

The isothermal crystallization of the PLLA/MWCNT nanocomposites was investigated for various MWCNT content, crystallization temperatures, and molecular weight of PLLA (i.e., with or without chain extension process). The exotherms at different crystallization temperatures are shown in Figure 4 for different representative samples and at different crystallization temperatures. It is obvious that the both functional and pristine $\mathrm{CNT}$ act as nucleating agents and increase the crystallization rate. Thus, heterogeneous nucleation was enhanced by incorporation of MWCNT with high
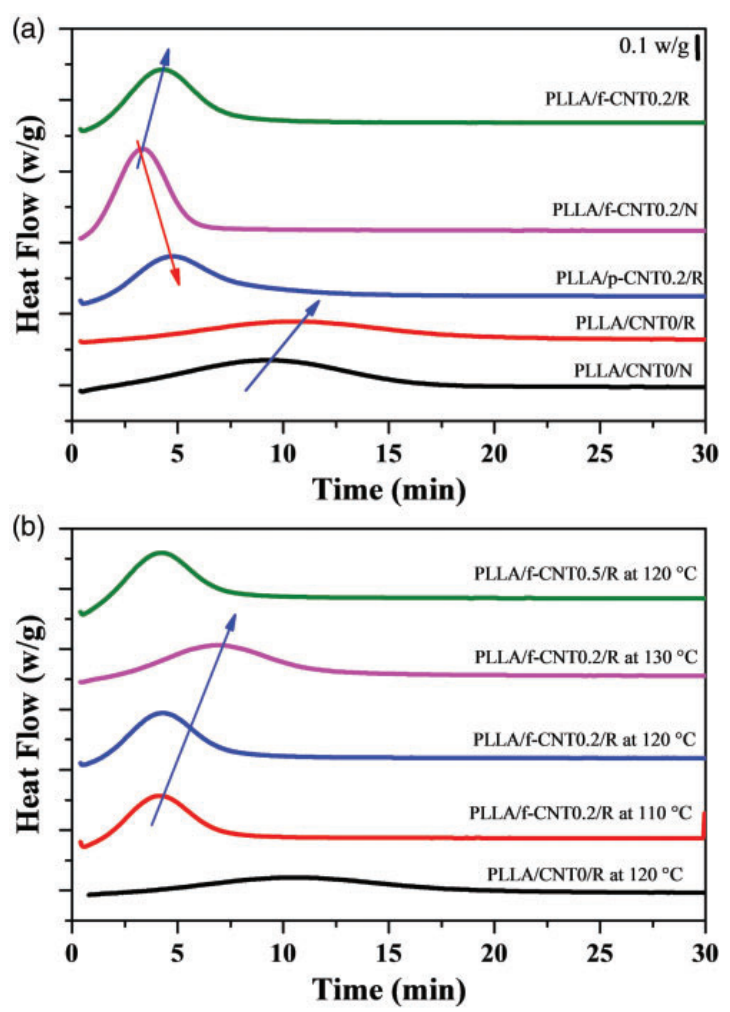

Figure 4. Isothermal DSC traces at $120^{\circ} \mathrm{C}$ (a) and different temperatures (b) to show the effect on the crystallization process caused by the incorporation of functionalized or pristine MWCNTs and chain extension (a), and MWCNT content and temperature (b). (a)

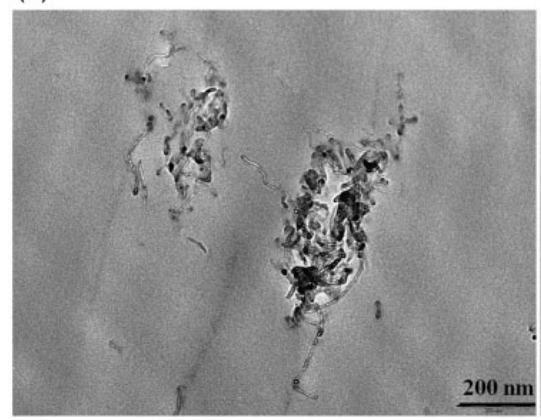

(b)

(c)

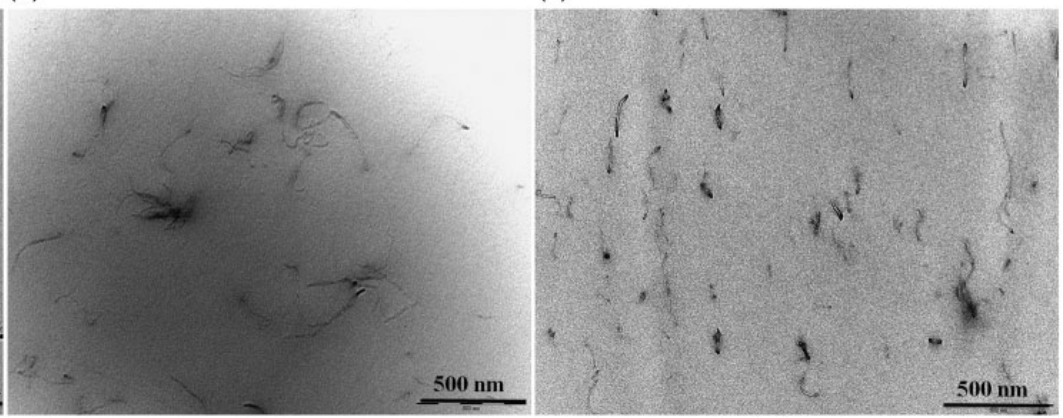

Figure 3. TEM images of PLLA/p-CNT0.2/N (a), PLLA/f-CNT0.2/N (b), and PLLA/f-CNT0.2/R (c) nanocomposites. 
surface area as then will also be discussed from optical microscopy studies. Figure 4(a) shows that PLA chain extension resulted in a shift of the exothermic peak to longer times (blue arrows), implying that the crystallization rate decreased. On the contrary, the effect of functionalization was scarce although the exothermic peak temperature slightly decreased (red arrow and blue curves in Figure 4(a) and (b)). Figure 4(b) shows the influence of crystallization temperature and MWCNT content for samples with similar molecular weight. Crystallization was logically faster (blue arrow) when temperature was decreased but a complex behavior was observed with variation of MWCNT contents (i.e., a maximum crystallization rate was observed for a $0.5 \mathrm{wt} \%$ ). Results are summarized in Table 1 for all studied samples at the three different isothermal temperatures that were considered.

The isothermal crystallization kinetics of PLLA/ CNT nanocomposites was investigated by evaluating the degree of crystallinity as a function of time at a constant temperature. The relative crystallinity $\left(X_{t}\right)$ for various crystallization times was calculated from the ratio of the area of the exothermic peak up to a time $t$ divided by the area of the total exotherm.
The relative crystallinity with crystallization time was calculated using

$$
X_{t}=\frac{\int_{0}^{t}\left(\frac{\mathrm{d} H}{\mathrm{~d} t}\right) \mathrm{d} t}{\int_{0}^{\infty}\left(\frac{\mathrm{d} H}{\mathrm{~d} t}\right) \mathrm{d} t}
$$

where $\frac{d H}{d t}$ is the rate of heat evolution.

The time evolution of relative crystallinity of representative PLLA/CNT nanocomposites is shown in Figure 5(a). All curves exhibited a sigmoidal dependence with time, being detected the development of secondary crystallization when the degree of crystallinity reached values around $0.8-0.9$. Secondary crystallization appeared at lower degrees of crystallinities when the MWCNT content increased (e.g., see PLLA/fCNT0.2/R and PLLA/f-CNT0.5/R curves).

The time required for completion of crystallization was shorter when CNT was incorporated and logically shorter when crystallization temperature decreased. Crystallization enthalpy, as a measurement of the absolute degree of crystallinity, was lower for related samples (i.e., having similar content and type of nanofiller) when crystallization temperature decreased and also when chain extension was performed due to higher molecular weight and different chain structure.

Table I. Main parameters of isothermal crystallization and Avrami analysis for PLLA samples and its nanocomposites.

\begin{tabular}{|c|c|c|c|c|c|c|c|c|}
\hline Sample & $\begin{array}{l}\text { Crystallization } \\
\text { temperature } \\
\left({ }^{\circ} \mathrm{C}\right)\end{array}$ & $\begin{array}{l}t_{c} \\
(\min )\end{array}$ & $\begin{array}{l}H \\
(\mathrm{~J} / \mathrm{g})\end{array}$ & $n$ & $\begin{array}{l}Z \times 10^{3} \\
\left(\min ^{-n}\right)\end{array}$ & $\begin{array}{l}k \times 10^{3} \\
\left(\min ^{-1}\right)\end{array}$ & $\begin{array}{l}\tau_{1 / 2}{ }^{a} \\
(\min )\end{array}$ & $\begin{array}{l}\tau_{1 / 2}{ }^{b} \\
(\mathrm{~min})\end{array}$ \\
\hline & 110 & 8.1 & 40.8 & 2.39 & 6.8 & 124 & 6.94 & 7.15 \\
\hline \multirow[t]{3}{*}{ PLLA/CNTO/N } & 120 & 9.2 & 46.2 & 2.39 & 5.1 & 110 & 7.82 & 8.16 \\
\hline & 130 & 14.5 & 52.0 & 2.44 & 1.3 & 66 & 13.0 & 13.5 \\
\hline & 110 & 2.7 & 38.0 & 2.12 & 125.2 & 375 & 2.24 & 2.10 \\
\hline \multirow[t]{3}{*}{ PLLA/f-CNT0.2/N } & 120 & 3.3 & 41.7 & 2.31 & 68.5 & 313 & 2.72 & 2.65 \\
\hline & 130 & 8.1 & 51.1 & 2.51 & 4.6 & 118 & 7.33 & 7.35 \\
\hline & 110 & 10.1 & 35.4 & 2.34 & 3.7 & 91 & 9.38 & 9.45 \\
\hline \multirow[t]{3}{*}{ PLLA/CNTO/R } & 120 & 10.4 & 36.5 & 2.45 & 2.7 & 89 & 9.63 & 9.67 \\
\hline & 130 & 16.1 & 39.4 & 2.81 & 0.4 & 62 & 14.1 & 14.3 \\
\hline & 110 & 4 & 35.8 & 2.39 & 26.9 & 221 & 3.89 & 3.67 \\
\hline \multirow[t]{3}{*}{ PLLA/p-CNT0.2/R } & 120 & 4.7 & 40.9 & 2.23 & 20.3 & 174 & 4.88 & 4.65 \\
\hline & 130 & 7.5 & 36.4 & 2.35 & 6.1 & 114 & 7.52 & 7.36 \\
\hline & 110 & 4.1 & 36.9 & 2.29 & 29.9 & 216 & 3.94 & 3.82 \\
\hline \multirow[t]{3}{*}{ PLLA/f-CNT0.2/R } & 120 & 4.3 & 40.2 & 2.25 & 29.7 & 210 & 4.04 & 3.95 \\
\hline & 130 & 7.0 & 44.7 & 2.39 & 7.5 & 129 & 6.67 & 6.45 \\
\hline & 110 & 3.8 & 41.3 & 2.18 & 40.9 & 232 & 3.65 & 3.49 \\
\hline \multirow[t]{2}{*}{ PLLA/f-CNT0.5/R } & 120 & 4.2 & 52.4 & 2.20 & 31.5 & 206 & 4.11 & 3.97 \\
\hline & 130 & 6.9 & 56.4 & 2.16 & 11.9 & 129 & 6.55 & 6.34 \\
\hline
\end{tabular}

${ }^{\mathrm{a}}$ From Avrami analysis.

${ }^{\mathrm{b}}$ From experimental data. 

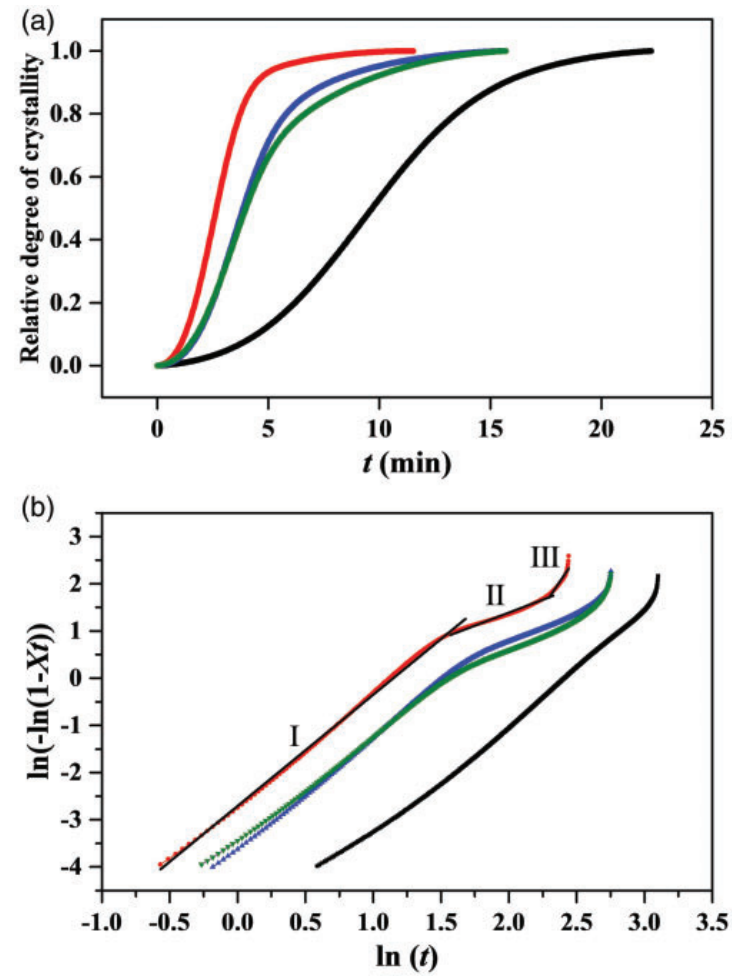

Figure 5. Relative degree of crystallinity versus time (a) and Avrami plots (b) for the isothermal crystallization at $120^{\circ} \mathrm{C}$ of PLLA/CNT0/R (black lines), PLLA/f-CNT0.2/N (red lines), PLLA/ f-CNT0.2/R (blue lines), and PLLA/f-CNT0.5/R (green lines).

The theory of Avrami was applied to analyze the isothermal crystallization kinetics of the different PLLA/CNT nanocomposites. To this end the following equations were employed ${ }^{39}$

$$
\begin{gathered}
X_{t}=1-\exp \left(-Z \mathrm{t}^{\mathrm{n}}\right) \\
\ln \left[-\ln \left(1-X_{t}\right)\right]=\ln Z+n \ln t \\
k=(Z)^{1 / \mathbf{n}} \\
\tau_{1 / 2}=(\ln 2 / Z)^{1 / n}
\end{gathered}
$$

where $X_{t}$ is the relative degree of crystallinity, $n$ is the Avrami constant, $k$ is the overall crystallization rate constant, $t$ is the relative crystallization time, $n$ is the Avrami exponent dependent on the nucleation mechanism and the crystal growth geometry, and $\tau_{1 / 2}$ is the crystallization half time.

The values of $n$ and $Z$ can be obtained from the slope and the intercept in the origin of $\ln (-\ln$ $(1-X t))$ versus $\ln (t)$ plots, respectively. The theoretical values of crystallization half time calculated from the Avrami equation $\left(\tau_{1 / 2}\right)$ can be compared with experimental values directly obtained from relative crystallinity curves (i.e., the time required to reach a crystallinity of 0.5 ) in order to verify the goodness of the Avrami analysis (Table 1).

Comparison between the kinetic data determined for the different systems allows deducing the following general trends:

1. The Avrami exponents have values in a narrow interval between 2.26 and 2.81 (average value of 2.36) that suggest a heterogeneous nucleation and a spherulitic growth. The exponent lower than the theoretical value of 3 suggests that physical constrictions are present, surely during the last crystallization steps. There are not significant differences of the Avrami exponent between the different samples, being only detected a trend to increase when the crystallization temperature did, suggesting that geometrical constrictions are minimized when crystallization rate decreases.

2. A good agreement is always observed between the theoretical and experimental crystallization half times and consequently the deduced Avrami parameters seem appropriate to explain the crystallization kinetics of all the considered systems.

3. The overall crystallization rate logically increased when the crystallization temperature decreases as consequence of an increased primary nucleation.

4. The overall crystallization rate decreases in chain extended systems as consequence of the increased molecular weight. Thus, for example, $0.124 \mathrm{~min}^{-1}$ and $0.091 \mathrm{~min}^{-1}$ were determined for PLA/CNT0/ $\mathrm{N}$ and PLA/CNT0/R samples, respectively, at a crystallization temperature of $110^{\circ} \mathrm{C}$. The effect of molecular weight was studied before ${ }^{40}$ and it was found that it significantly affects the crystallization kinetics, decreasing the crystallization rate by the increase of molecular weight.

5. The overall crystallization rate increases with the nanofiller content (e.g., $0.091 \mathrm{~min}^{-1}, 0.216 \mathrm{~min}^{-1}$, and $0.232 \mathrm{~min}^{-1}$ for PLLA/CNT0/R, PLLA/fCNT0.2/R, and PLLA/f-CNT0.5/R samples, respectively, at $110^{\circ} \mathrm{C}$ ), suggesting a clear nucleation effect. Nevertheless, differences between samples having 0.2 and $0.5 \mathrm{wt} \%$ were very scarce for the higher temperatures of $120^{\circ} \mathrm{C}$ and $130^{\circ} \mathrm{C}$. These results are in good agreement with previously reported results. ${ }^{41}$

6. The overall crystallization rate of composites having functionalized nanotubes was slightly higher than that determined for composites derived from pristine nanotubes (e.g., $0.174 \mathrm{~min}^{-1}$ and $0.210 \mathrm{~min}^{-1}$ for PLLA/p-CNT0.2/R and PLLA/f-CNT0.2/R samples, respectively, at $120^{\circ} \mathrm{C}$ ). In this case, functionalization seems to improve the nucleation effect due to 
a better dispersion of nanotubes in the polymer matrix.

Optical microscopy studies were also performed in order to see the effect of nucleation and compare the crystal growth rates. Figure 6 shows optical micrographs for crystallizations carried out at different temperatures for two representative systems: PLLA/CNT0/ $\mathrm{R}$ and PLLA/f-CNT0.2/R, which allow understanding the role displayed by nanotubes in the crystallization process. Spherulites with a fibrillar morphology were always developed, being their diameter lower as crystallization temperature decreased as consequence of the increased nucleation. Sizes were also clearly smaller with the incorporation of nanotubes, demonstrating their nucleation effect. Thus, for example, 9600 and 190 nuclei $/ \mathrm{mm}^{2}$ were measured for samples with and without nanotubes crystallized at $130^{\circ} \mathrm{C}$. Nucleation was practically athermal and consequently the number of nuclei was kept constant along crystallization time.

Figure 7 compares the spherulitic growth rates evaluated for the same samples, being clear that the presence of nanotubes played a very scarce influence. However, a slight decrease on the crystallization rate was observed when nanotubes were incorporated. This feature seems an indication of a disturbing effect on the motion of polymer chains, which appear more relevant at the assayed temperature of $110^{\circ} \mathrm{C}$ (i.e., $2.22 \mu \mathrm{m} / \mathrm{min}$ with respect to $2.10 \mu \mathrm{m} / \mathrm{min}$ ) where crystallization becomes limited by the chain transport energy. It is also clear that the effect of nanotubes on the crystal growth rate is scarce in comparison with their influence on nucleation.

\section{Nonisothermal crystallization from the melt}

Crystallization kinetic analysis from nonisothermal conditions is rather more complicated since crystallization becomes a succession of processes performed under different degrees of supercoolings. Nevertheless, this study is highly interesting since samples are usually processed under nonisothermal conditions. DSC cooling traces were recorded for the studied polymers and nanocomposites to get data from the crystallization peaks as a function of temperature and time (after appropriate unit conversion).
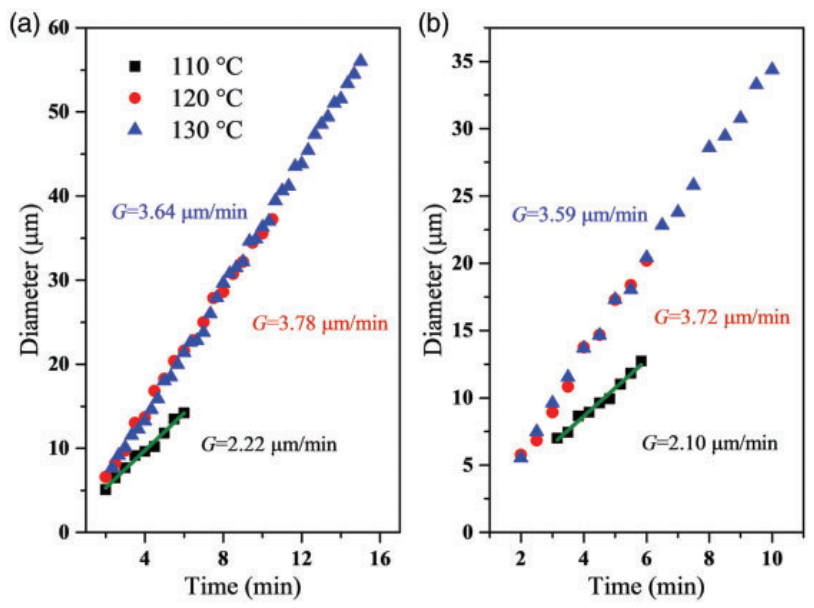

Figure 7. Spherulite diameter as a function of time at different isothermal crystallization temperatures for (a) PLLA/CNTO/R and (b) PLLA/f-CNT0.2/R. Straight lines are fitted to the experimental data to calculate the growth rate $(G)$ from the slope.

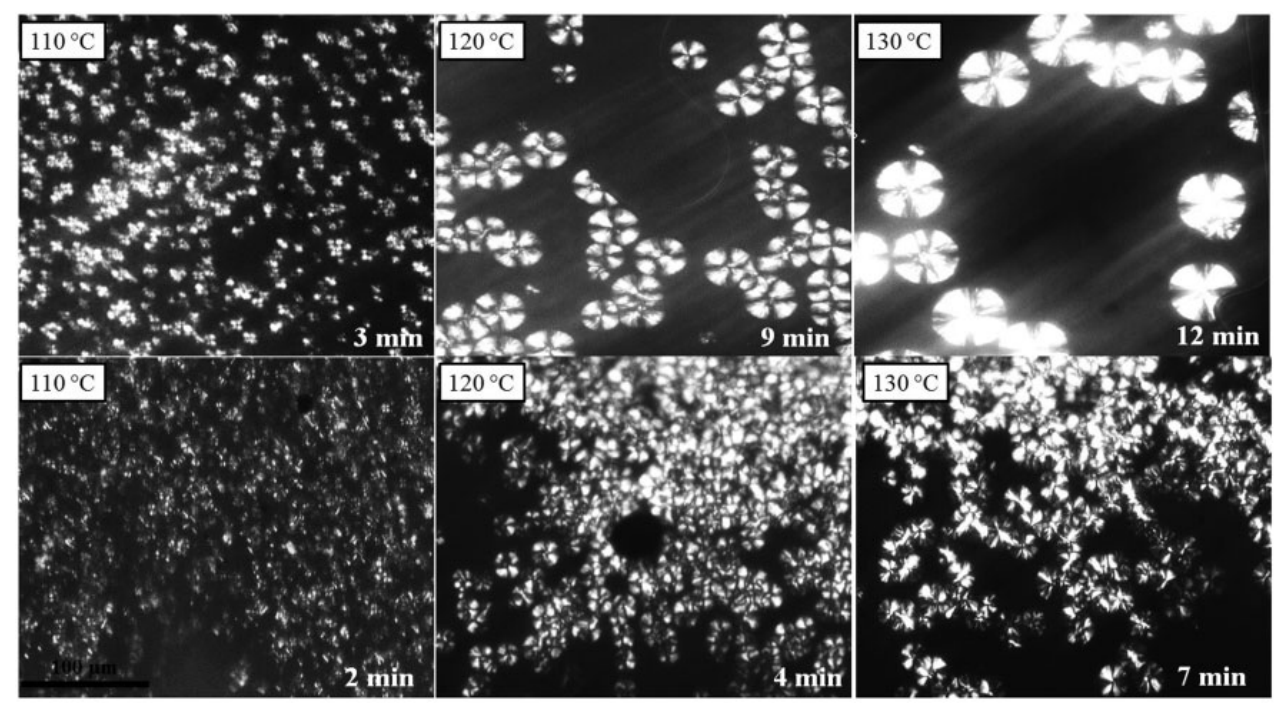

Figure 6. Polarized optical micrographs of PLLA/CNTO/R (top images) and PLLA/f-CNT0.2/R (bottom images) taken at the indicated crystallization temperatures and times. 
Calorimetric data were used to determine the relative degree of crystallinity at any temperature, $X(T)$, for all cooling rates by the expression

$$
X(T)=\frac{\int_{T_{0}}^{T_{c}}\left(\mathrm{~d} H_{c} / \mathrm{d} T\right) \mathrm{d} T}{\int_{T_{0}}^{T_{\infty}}\left(\mathrm{d} H_{c} / \mathrm{d} T\right) \mathrm{d} T}
$$

where $\mathrm{d} H_{c}$ is the enthalpy of crystallization released within an infinitesimal temperature range $\mathrm{d} T, T_{0}$ denotes the initial crystallization temperature and $T_{\mathrm{c}}$ and $T_{\infty}$ are the crystallization temperatures at time $t$ and after completion of the crystallization process, respectively. Thus, the denominator corresponds to the overall enthalpy of crystallization for specific heating/cooling conditions.

The crystallization temperature, $T_{c}$, can be converted to crystallization time, $t$, using the well-known relationship for nonisothermal crystallization processes which is strictly valid when the sample experiences the same thermal history as designed by the $\mathrm{DSC}^{42}$

$$
t=\frac{T_{0}-T_{c}}{a}
$$

where $T_{0}$ is the temperature at which crystallization begins $(t=0)$ and $a$ is the value of the cooling rate.
Variation of the time-dependent degree of crystallinity, $X_{t}$, determined from equations (6) and (7) allows a typical Avrami analysis to be performed according to equations (2) to (4).

Figure 8(a) compares the crystallization exotherms, the evolutions of $X_{t}$ and $X_{T}$ and the Avrami plots for several PLLA and nanocomposite samples at the lower cooling rate (i.e., $2.5^{\circ} \mathrm{C} / \mathrm{min}$ ), while values of main crystallization parameters at the four cooling rates are summarized in Table 2.

Avrami analyses lead to the following conclusions, which in general are similar than those determined from the isothermal study:

1. The Avrami exponent had values in the interval between 2.39 and 3.12 (average value of 2.72), which are substantially higher than those determined from isothermal conditions, although still pointed out that generally a heterogeneous nucleation and a spherulitic growth was characteristic. Cautions should be taken since it is known that analyses may lose physical sense in nonisothermal studies and the exponent could merely correspond to a fitting parameter. In this sense, note that some high exponents like 3.12 were determined, being these values always detected at the lowest cooling rate where effects corresponding to a sporadic nucleation (theoretical exponent of 4 for a spherulitic (a)
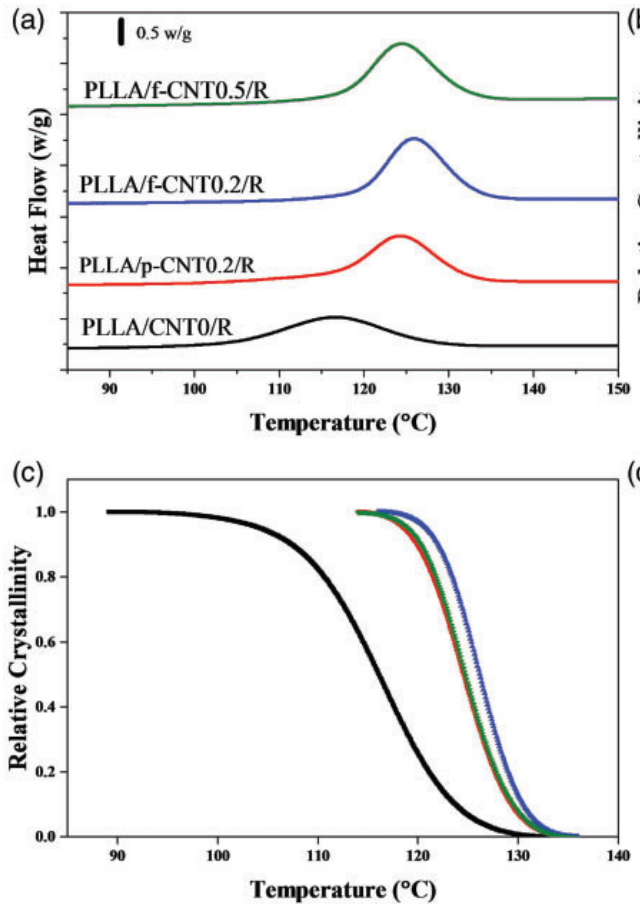

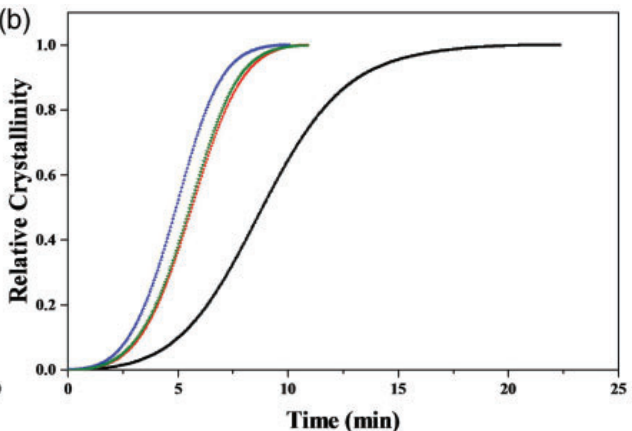

(d)

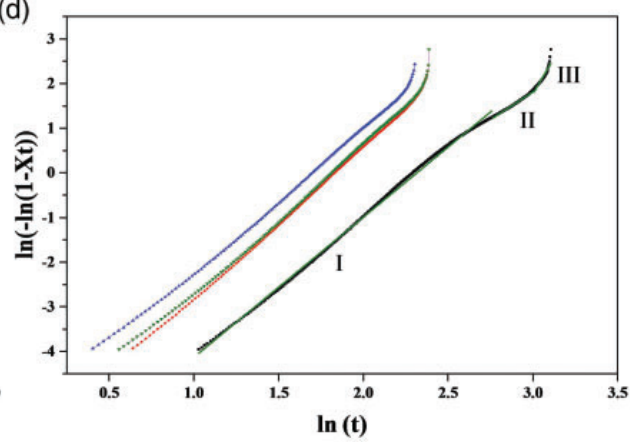

Figure 8. DSC cooling thermograms (a), relative crystallinity versus time (b), relative crystallinity versus temperature (c) and Avrami plots (d) for representative samples of PLLA and its nanocomposites. The cooling rate was $2.5^{\circ} \mathrm{C} / \mathrm{min}$. 
Table 2. Kinetic parameters for the nonisothermal crystallization of PLLA and its nanocomposites.

\begin{tabular}{|c|c|c|c|c|c|c|c|}
\hline Sample & $\begin{array}{l}\text { Cooling rate } \\
\left({ }^{\circ} \mathrm{C} / \mathrm{min}\right)\end{array}$ & $T_{c}\left({ }^{\circ} \mathrm{C}\right)$ & $\begin{array}{l}H_{c} \\
(\mathrm{~J} / \mathrm{g})\end{array}$ & $n$ & $\begin{array}{l}Z \times 10^{3} \\
\left(\min ^{-n}\right)\end{array}$ & $\begin{array}{l}k \times 10^{3} \\
\left(\min ^{-1}\right)\end{array}$ & $\begin{array}{l}t_{1 / 2} \\
(\min )\end{array}$ \\
\hline & 2.5 & 112.3 & 36.4 & 2.71 & 40 & 303 & 9.72 \\
\hline \multirow[t]{4}{*}{ PLLA/CNTO/N } & 5 & 100.3 & 4.6 & 2.75 & 401 & 717 & 4.91 \\
\hline & 7.5 & 99.1 & 1.3 & 2.65 & 510 & 822 & 3.83 \\
\hline & 10 & 98.4 & 0.6 & 2.51 & 780 & 925 & 1.91 \\
\hline & 2.5 & 118.2 & 38.3 & 3.12 & 40 & 356 & 5.87 \\
\hline \multirow[t]{4}{*}{ PLLA /f-CNT0.2/N } & 5 & 104.2 & 31.8 & 2.93 & 438 & 755 & 3.75 \\
\hline & 7.5 & 100.7 & 17.3 & 2.86 & 562 & 852 & 3.13 \\
\hline & 10 & 97.8 & 5.7 & 2.73 & 775 & 919 & 2.14 \\
\hline & 2.5 & 116.5 & 29.3 & 2.93 & 32 & 310 & 8.88 \\
\hline \multirow[t]{4}{*}{ PLLA/CNTO/R } & 5 & 104.7 & 5.2 & 2.60 & $44 I$ & 729 & 4.39 \\
\hline & 7.5 & 103.6 & 3.6 & 2.55 & 629 & 862 & 3.73 \\
\hline & 10 & 97.2 & 0.4 & 2.42 & 769 & 911 & 2.31 \\
\hline & 2.5 & 124.2 & 35.2 & 3.01 & 50 & 370 & 5.68 \\
\hline \multirow[t]{4}{*}{ PLLA/P-CNT0.2/R } & 5 & 110.1 & 22.2 & 2.67 & 452 & 743 & 3.86 \\
\hline & 7.5 & 105.2 & 10.4 & 2.61 & 548 & 794 & 3.21 \\
\hline & 10 & 104.1 & 5.5 & 2.44 & 785 & 914 & 2.29 \\
\hline & 2.5 & 125.9 & 36.4 & 3.07 & 69 & 430 & 4.92 \\
\hline \multirow[t]{4}{*}{ PLLA/f-CNT0.2/R } & 5 & 113 & 27.6 & 2.89 & $46 I$ & 765 & 3.39 \\
\hline & 7.5 & 110 & 13.5 & 2.71 & 579 & 817 & 2.83 \\
\hline & 10 & 106.6 & 7.4 & 2.54 & 784 & 916 & 2.13 \\
\hline & 2.5 & 124.5 & 36.6 & 3.02 & 66 & 406 & 5.57 \\
\hline \multirow[t]{3}{*}{ PLLA/f-CNT0.5/R } & 5 & III.I & 26.5 & 2.79 & 439 & 744 & 3.86 \\
\hline & 7.5 & 107.5 & 12.3 & 2.58 & 497 & 835 & 3.56 \\
\hline & 10 & 105.1 & 8.8 & 2.39 & 776 & 913 & 2.23 \\
\hline
\end{tabular}

morphology) could not be completely discarded. Significant differences between the Avrami exponents evaluated for the studied samples were not detected. The exponent tended to diminish with the increase of the cooling rate, suggesting that higher geometric constrictions existed when the samples were rapidly crystallized.

2. The overall crystallization rate logically increased when the cooling rate increased.

3. The overall crystallization rate did not change significantly or even increased when chain extension was performed $\left(0.303 \mathrm{~min}^{-1}\right.$ and $0.310 \mathrm{~min}^{-1}$ for PLLA/CNT0/N and PLLA/CNT/R, respectively, at $2.5^{\circ} \mathrm{C} / \mathrm{min}$ ). This result seems in contradiction with that attained from isothermal crystallization. Note however, that the high molecular sample may crystallize before (i.e., high $T_{c}$ value) since a lower supercooling is required.

4. The overall crystallization rate was maximum for a nanofiller content of $0.2 \mathrm{wt} \%$, suggesting an agglomeration effect when the content was $0.5 \mathrm{wt} \%$. This difference could be observed at low cooling rates $\left(0.430 \mathrm{~min}^{-1}\right.$ and $0.406 \mathrm{~min}^{-1}$ for PLLA/f-CNT0.2/R and PLLA/f-CNT0.5/R, respectively at $2.5^{\circ} \mathrm{C} / \mathrm{min}$ ), but not under isothermal conditions.

5. The overall crystallization rate of composites having functionalized nanotubes was higher than that determined for composites derived from nonfunctionalized nanotubes (e.g., $0.370 \mathrm{~min}^{-1}$ and $0.430 \mathrm{~min}^{-1}$ for PLLA/p-CNT0.2/R and PLLA/f-CNT0.2/R samples, respectively, at $2.5^{\circ} \mathrm{C} / \mathrm{min}$ ). In this case, functionalization seems again to improve the effectivity of nucleation due to better dispersion of nanotubes in the polymer matrix. The preceding and the present point indicate that incorporation of $0.2 \mathrm{wt} \%$ of functionalized MWCNTs lead to the higher crystallization rate.

6. Final crystallinities were logically higher for all samples when the cooling rate decreased. Furthermore, the incorporation of $0.2 \mathrm{wt} \%$ of functionalized MWCNTs lead to an increase of the final crystallinity.

A completely different approach to perform nonisothermal studies was developed by $\mathrm{Mo}$ and 
coworkers. ${ }^{43}$ They proposed a different kinetic model by combining the well-known Ozawa and Avrami equations. As the degree of crystallinity was related to the cooling rate $a$ and the crystallization time $t$ or temperature $T_{\mathrm{c}}$, a relationship between $a$ and $t$ was defined for a given degree of crystallinity

$$
\ln a=\ln F\left(T_{c}\right)-b \ln t
$$

where $F\left(T_{c}\right)$ refers to the value of cooling rate that should be chosen at unit crystallization time, when the system reaches a certain degree of crystallinity, $b$ is the ratio between Avrami and Ozawa exponents.

According to equation (8) at a given degree of crystallinity the plot of $\ln a$ against $\ln t$ will give a straight line with an intercept of $\ln F\left(T_{c}\right)$ and a slope of $-b$. Linear plots were derived for all studied systems, as shown in Figure 9 for a representative sample, being consequently possible to determine $F\left(T_{c}\right)$ and $b$ values as summarized in Table 3.

Values of $b$ were close to 1 when samples were not loaded with MWCNTs (i.e., average value of 1.17) and consequently a good agreement was found between exponents calculated through the Avrami and Ozawa models. Incorporation of MWCNTs lead to a higher average value (i.e., 1.74) and specifically the highest deviation was found for the PLLA/f-CNT0.2/R sample (2.13).

More interestingly $F\left(T_{c}\right)$ values increased with the relative degree of crystallinity and furthermore changed according to the MWCNT content and their functionalization. Thus, values compared for the different samples at a given conversion indicate a good agreement between the deduced trends from nonisothermal crystallization rates (i.e., $k$ ). Thus, the highest $F\left(T_{c}\right)$ values corresponded to PLLA/f-CNT0.2/R, while

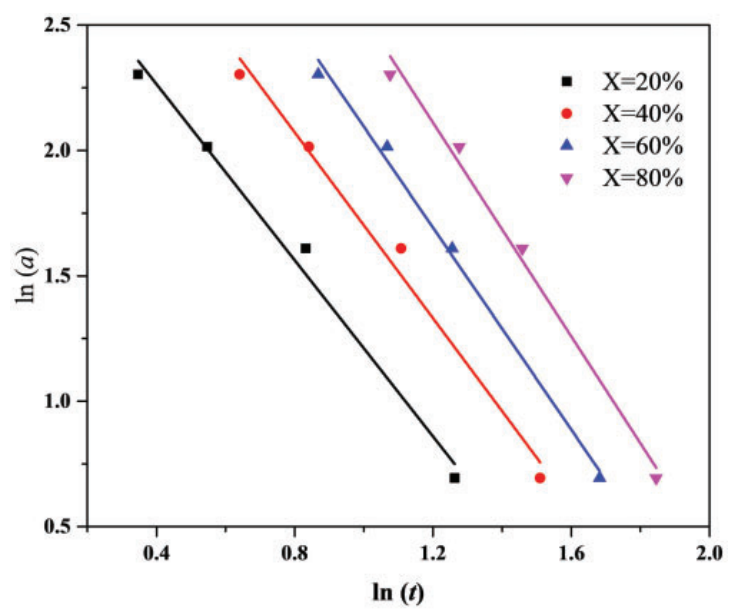

Figure 9. Plots of In (a) versus In ( $t$ ) for nonisothermal crystallization of PLLA/f-CNT0.2/R performed at the indicated crystallinities. lower values were found when other contents were considered (i.e., $F\left(T_{c}\right)$ was lower for a $0.5 \mathrm{wt} \%$ ). Lower $F\left(T_{c}\right)$ values were also determined when nonfunctionalized MWCNTs were incorporated. It is also interesting to note that results were more confuse when PLLA/ CNT0/R and PLLA/CNT0/N samples were compared since the chain extended sample displayed lower $F\left(T_{c}\right)$ values at low conversion and higher at high conversions, a feature that may be somehow related with the controversial results attained from isothermal and nonisothermal analyses of these two samples.

A third kind of nonisothermal analyses correspond to the evaluation of the effective energy barrier for the crystallization process. The differential isoconversional method of Friedman ${ }^{44}$ and the advanced integral isoconversional method of Vyazovkin ${ }^{45}$ are probably the most usual methodologies. The method of Friedman is based on the equation

$$
\ln \left(\frac{\mathrm{d} X}{d t}\right)_{X, i}=A-\frac{\Delta E_{X}}{R T_{X, i}}
$$

Table 3. Values of $b$ and $F\left(T_{c}\right)$ versus degree of crystallinity based on Mo's treatment for the different PLLA samples and their

\begin{tabular}{|c|c|c|c|}
\hline Sample & $X(T)(\%)$ & $F\left(T_{c}\right)$ & $b$ \\
\hline & 20 & 17.7 & 1.15 \\
\hline & 40 & 24.4 & 1.15 \\
\hline \multirow[t]{4}{*}{ PLLA/CNTO/N } & 60 & 29.9 & 1.12 \\
\hline & 80 & 38.9 & 1.14 \\
\hline & 20 & 17.7 & 1.47 \\
\hline & 40 & 31.5 & 1.59 \\
\hline \multirow[t]{4}{*}{ PLLA/f-CNT0.2/N } & 60 & 44.6 & 1.62 \\
\hline & 80 & 64.3 & I.7I \\
\hline & 20 & 16.9 & 1.14 \\
\hline & 40 & 23.2 & 1.16 \\
\hline \multirow[t]{4}{*}{ PLLA/CNTO/R } & 60 & $3 I . I$ & 1.19 \\
\hline & 80 & 40.6 & 1.21 \\
\hline & 20 & 18.2 & 1.52 \\
\hline & 40 & 32.0 & 1.63 \\
\hline \multirow[t]{4}{*}{ PLLA/p-CNT0.2/R } & 60 & 52.2 & 1.78 \\
\hline & 80 & 80.9 & 1.85 \\
\hline & 20 & 19.4 & 1.76 \\
\hline & 40 & 34.9 & 1.85 \\
\hline \multirow[t]{4}{*}{ PLLA/f-CNT0.2/R } & 60 & 60.8 & 2.01 \\
\hline & 80 & 106.6 & 2.13 \\
\hline & 20 & 19.5 & 1.59 \\
\hline & 40 & 34.2 & I.7I \\
\hline \multirow[t]{2}{*}{ PLLA/f-CNT0.5/R } & 60 & 55.5 & 1.82 \\
\hline & 80 & 90.9 & 1.93 \\
\hline
\end{tabular}
selected composites. 
where $d X / d t$ is the instantaneous crystallization rate as a function of time at a given conversion. According to this method, the $X(t)$ function obtained from the integration of the experimentally measured crystallization rates is initially differentiated with respect to time to obtain the instantaneous crystallization rate, $d X / d t$. Furthermore, by selecting appropriate degrees of crystallinity (i.e., from $5 \%$ to $95 \%$ ) the values of $d X / d t$ at a specific $X$ are correlated to the corresponding crystallization temperature at this conversion, that is, $T_{X}$. Then by plotting the left hand side of equation (9) with respect to $1 / T_{X}$, a straight line must be obtained with a slope equal to $\Delta E_{X} / R$. As an example, plots of $\ln (d X / d t)$ versus $1 / T_{X}$ for the PLLA/f-CNT0.2/R at different relative crystallinities are given in Figure 10(a). Bell shape curves are obtained at different cooling rates,
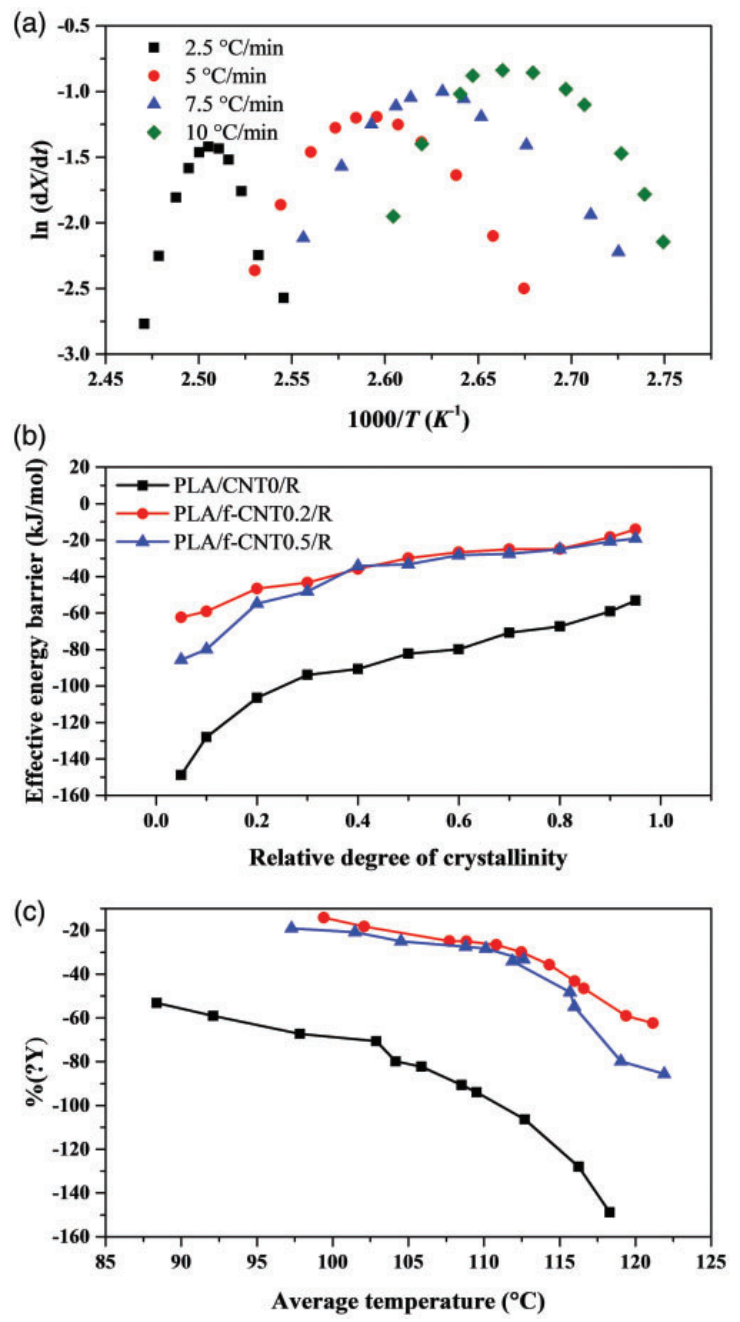

Figure 10. Friedman plots of $\ln (d X / d t)$ for PLLA/f-CNT0.2/R for different cooling rates (a), effective energy barrier versus relative degree of crystallinity (b), and average temperature (c) for the indicated samples. permitting thus the calculation of the effective energy barrier at different degrees of crystallinity.

The dependence of the effective energy barrier with the extent of relative crystallinity and the average temperature for the neat PLLA and PLLA/CNT nanocomposites incorporating 0.2 and $0.5 \mathrm{wt} \%$ of functionalized MWCNTs are shown in Figure 10(b) and (c).

Values of $\Delta E$ clearly increased with the increase of the relative degree of crystallinity (Figure 10(b)), which means with decreasing crystallization temperature (Figure 10(c)). In all cases, the effective activation energy took great negative values at low degrees of crystallinity that is at low supercooling degrees. Note that at these temperatures close to the melting point, the crystallization process is mainly dominated by the secondary nucleation process and not from the molecular transport. Activation energy increased progressively (i.e., the crystallization rate increased) as the temperature decreased, as discussed by Vyazovkin and Dranca. ${ }^{46}$ This feature shows the expected behavior for crystallizations performed at temperatures higher than those associated with the maximum crystallization rate (i.e., higher than those were the process was controlled by the energy transport barrier). Comparison of
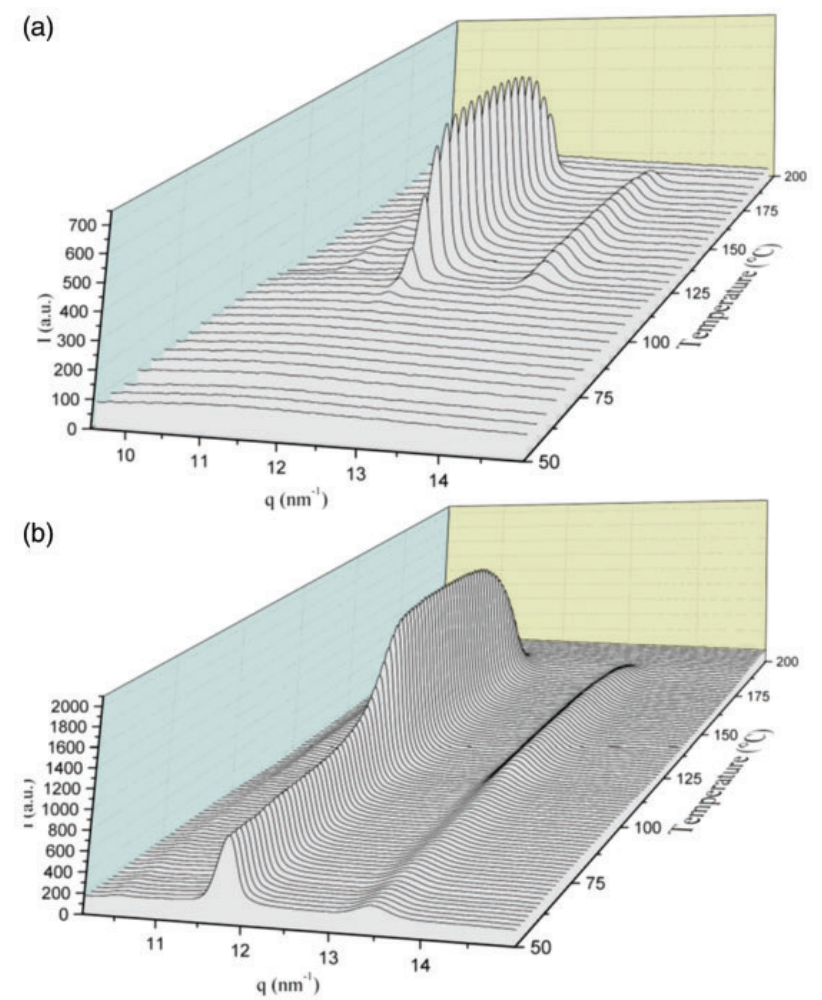

Figure II. WAXD profiles of amorphous (a) and semicrystalline (b) samples of PLLA/CNTO/R taken during heating $\left(10^{\circ} \mathrm{C} /\right.$ $\mathrm{min}$ ). Samples were previously quenched in liquid nitrogen (a) and cooled at a controlled rate of $10^{\circ} \mathrm{C} / \mathrm{min}$ (b) from the melt state. 
the activation energies for nanocomposites having 0.2 and $0.5 \mathrm{wt} \%$ of functionalized nanotubes showed a great similarity except at very low supercoolings where the crystallization process seems to be enhanced for samples with the $0.2 \mathrm{wt} \%$ content, This feature is in agreement with the nonisothermal Avrami analysis that pointed out a lower crystallization rate when the cooling rate was the lowest (i.e., $2.5^{\circ} \mathrm{C} / \mathrm{min}$ ). Activation energy was clearly more negative for the neat PLLA supporting again a more difficult crystallization process. In fact, it has been indicated from Lauritzen-Hoffman analysis of secondary nucleation that the incorporation of MWCNTs into a polymer matrix can lower the work required in folding the macromolecular chains. ${ }^{47-49}$ In addition, a different behavior was found in the work of Papageorgiou et al. ${ }^{18}$ which studied the effect of filler type on nonisothermal crystallization of PLA. In their work, among the three nanofiller (i.e., fumed silica nanoparticles, montmorillonite (MMT), and oxidized MWCNT), the MWCNT influenced the activation energy more than other filler especially at the beginning of crystallization.

\section{SAXS and WAXD studies on the cold crystallization process of polylactide and its nanocomposites with MWCNTs}

Figure 11 shows the WAXD profiles taken during the heating of samples which cooled at different cooling rates from the melt state. It is obvious that completely amorphous and semicrystalline samples can be obtained depending on the cooling process as can be deduced from the trend shown in Table 2. All samples, as it is also well-known for PLLA, are susceptible to cold crystallize in a subsequent heating run, being interesting to determine the role played by the incorporation of MWCNTs.

According to the WAXD spectra shown in Figure 12, PLLA and its nanocomposites always crystallized according to a packing of molecules having a $10_{3}$ helical conformation, being possible both the named $\alpha$ and $\alpha^{\prime}$ structures. ${ }^{50,51}$ The typical diffraction pattern has strong Bragg peaks at 0.542, 0.472, and $0.403 \mathrm{~nm}$ which could be indexed as the $(200)+(110)$, (203), and (015) reflections. Furthermore, an amorphous halo at $0.554 \mathrm{~nm}$ could clearly be detected
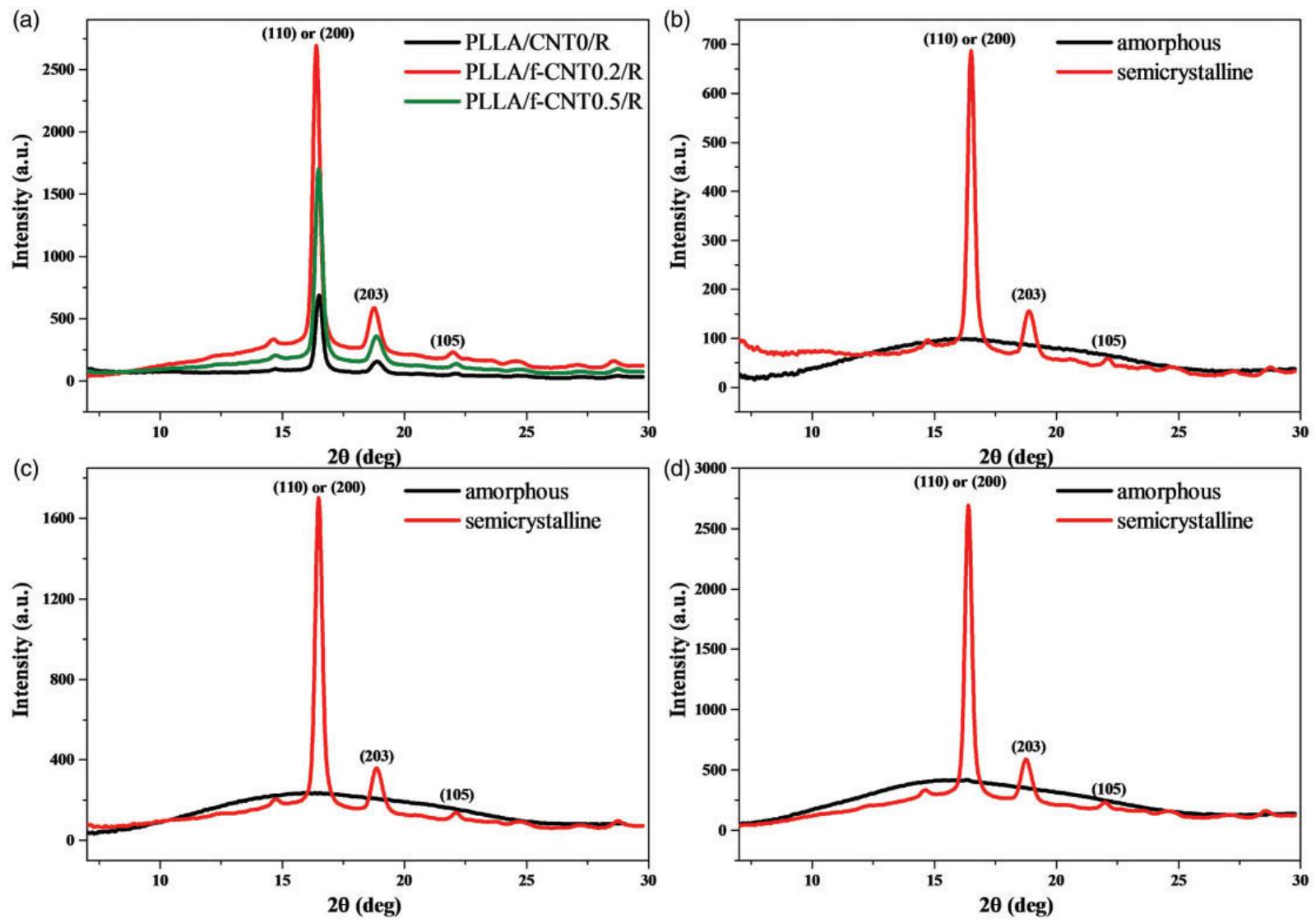

Figure 12. WAXD profiles for (a) PLLA nanocomposites, (b) PLLA/CNT0/R, (c) PLLA/f-CNT0.2/R, and (d) PLLA/f-CNT0.5/R after cold crystallization. Samples were amorphous before heating (black profiles in (b), (c), and (d)). 
depending on the sample and the cooling rate. Patterns in Figure 12 showed that samples were amorphous after being quenched from the melt and were able to cold crystallize in a different degree, depending on the percentage of MWCNTs that was incorporated. Specifically analyses were performed for chain extended PLLA incorporating $0,0.2$, and $0.5 \mathrm{wt} \%$ of functionalized MWCNTs, being logically increased the relative intensity of the amorphous halo when the MWCNT content increased.

SAXS analyses would be useful to evidence if the selected cooling rate and the presence of MWCNTs had an influence on the morphology of crystals

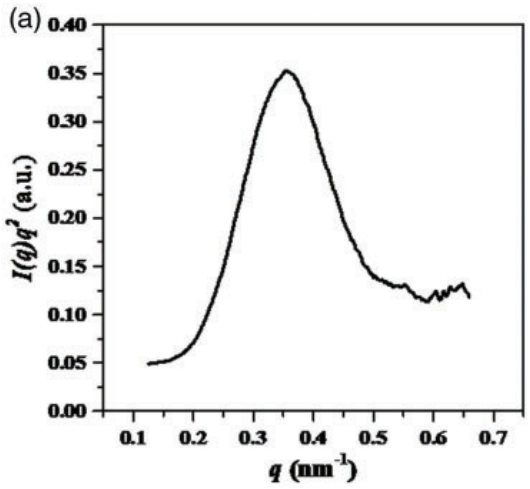

obtained after cold crystallization. Note that the similar densities of the amorphous and crystalline phases of PLA at room temperature precluded an analysis of the sample after crystallization from the melt state. On the contrary, a SAXS peak was clearly distinguished after the cold crystallization process that took place around $140^{\circ} \mathrm{C}$.

All studied samples had a clear SAXS peak after cold crystallization as shown in Figure 13(a) for PLLA as a representative sample. This peak was analyzed through a typical electron density correlation function, $K(z)$, as shown in Figure 13(b). Under the assumption of a biphasic model consisting of an

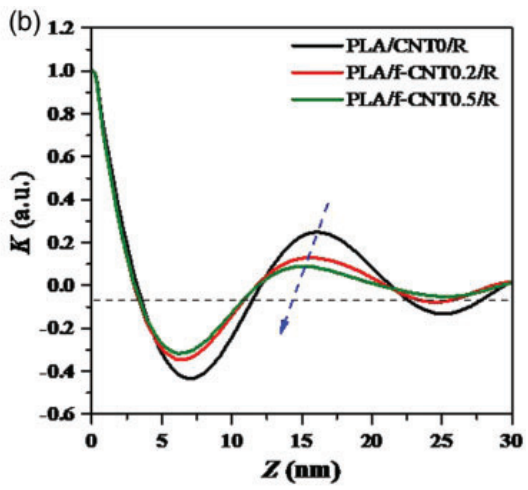

Figure 13. Typical SAXS observed after cold crystallization $\left(T=140^{\circ} \mathrm{C}\right)$ of PLLA/CNTO/R (a) and one-dimensional electron density correlation function $K(z)$ for pure PLLA and PLLA with 0.2 and $0.5 \mathrm{wt} \%$ of functionalized MWCNTs. Samples were cooled from the melt at a cooling rate of $10^{\circ} \mathrm{C} / \mathrm{min}$ and then heated at a rate of $10^{\circ} \mathrm{C} / \mathrm{min}$.

Table 4. Structural parameters of pure PLLA and PLLA with 0.2 and $0.5 \mathrm{wt} \% \mathrm{f}-\mathrm{CNT}$ at the end of cold crystallization.

\begin{tabular}{|c|c|c|c|c|c|c|}
\hline Sample & Cooling rate $\left({ }^{\circ} \mathrm{C} / \mathrm{min}\right)$ & $q_{\max }\left(\mathrm{nm}^{-1}\right)$ & $L\left(q_{\max }\right)(\mathrm{nm})$ & $I_{a}(\mathrm{~nm})$ & $I_{c}(\mathrm{~nm})$ & $L_{\gamma}(\mathrm{nm})$ \\
\hline \multirow[t]{7}{*}{ PLLA/CNTO/R } & Quenching & 0.309 & 20.32 & 3.6 & 14.2 & 17.8 \\
\hline & 10 & 0.355 & 17.69 & 3.1 & 12.8 & 15.9 \\
\hline & 7.5 & 0.354 & 17.74 & 2.8 & 12.0 & 14.8 \\
\hline & 5 & 0.351 & 17.89 & 2.8 & 12.0 & 14.8 \\
\hline & 2.5 & 0.347 & 18.09 & 2.8 & 12.0 & 14.8 \\
\hline & Quenching & 0.294 & 21.6 & 4.0 & 14.7 & 18.7 \\
\hline & 10 & 0.351 & 17.89 & 3.0 & 12.7 & 15.7 \\
\hline \multirow[t]{3}{*}{ PLLA/f-CNT0.2/R } & 7.5 & 0.376 & 16.70 & 2.8 & $1 \mathrm{I} .4$ & 14.2 \\
\hline & 5 & 0.378 & 16.61 & 2.8 & 11.3 & 14.1 \\
\hline & 2.5 & 0.368 & 17.06 & 2.8 & $1 \mathrm{l} .4$ & 14.2 \\
\hline \multirow[t]{5}{*}{ PLLA/f-CNT0.5/R } & Quenching & 0.306 & 20.52 & 3.7 & 14.3 & 18.0 \\
\hline & 10 & 0.356 & 17.64 & 2.8 & 12.0 & 14.8 \\
\hline & 7.5 & 0.376 & 16.70 & 2.7 & 11.2 & 13.9 \\
\hline & 5 & 0.372 & 16.88 & 2.7 & II.I & 13.8 \\
\hline & 2.5 & 0.361 & 17.39 & 2.7 & 11.2 & 13.9 \\
\hline
\end{tabular}

Note: Samples were previously cooled from the melt at the indicated rates. 

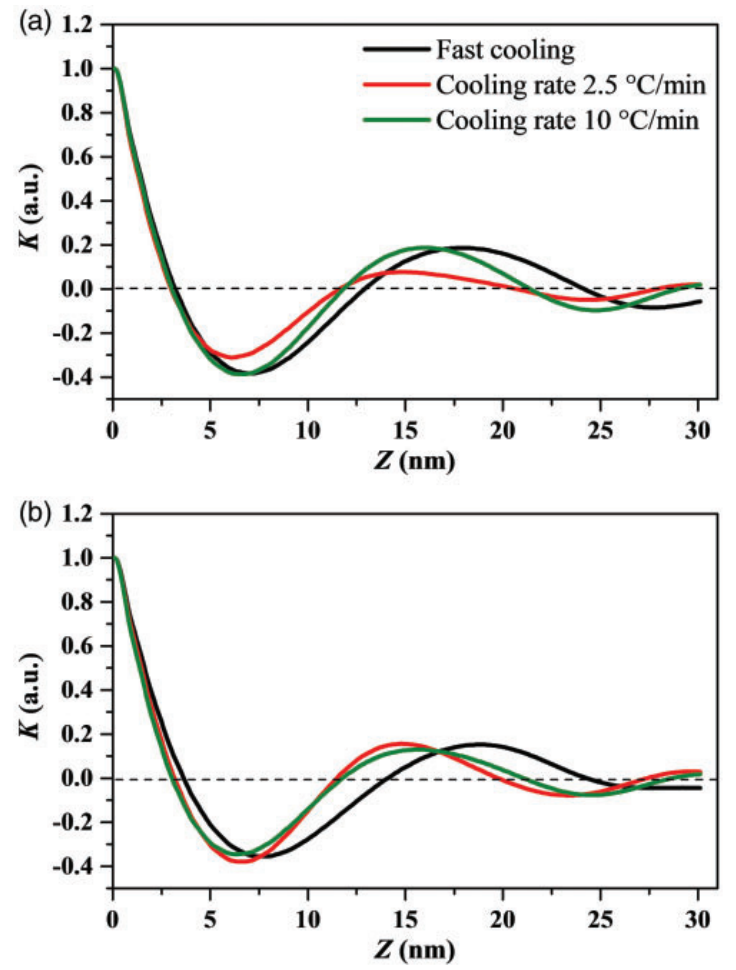

Figure 14. One-dimensional correlation functions for PLLA/ CNTO/R (a) and PLLA/f-CNT0.2/R (b). Samples were cooled at the indicated rates from the melt sate.

alternately stacked structure of crystalline and amorphous layers, $K(z)$ is defined by the following equation ${ }^{52}$

$$
K(z)=2 \pi^{-1} \int_{0}^{\infty} q^{2} I(q) \cos (q z) \mathrm{d} q
$$

where $I(q)$ is the experimental SAXS intensity at a given $q$, and $z$ is the correlation distance. Various points of the $K(z)$ curve are useful to get morphological parameters. The deduced thickness of the amorphous layer $\left(l_{a}\right)$, the mean lamellar thickness $\left(l_{c}\right)$, and the long period $\left(L_{\gamma}=l_{a}+l_{c}\right)$ are tabulated in Table 4 .

For all samples, the values of $l_{a}, l_{c}$, and $L_{\gamma}$ decreased when the cooling rate decreased. It seems that the cold crystallization process could render bigger crystalline entities in the absence of previously formed crystalline domains (i.e., when samples were rapidly cooled). By contrast, geometrical constrictions lead to smaller crystalline entities. This effect had also a great repercussion on the morphology of cold crystallized samples when MWCNTs were added (Figure 14). The higher crystallinity attained after cooling when the nucleating effect was high (i.e., when NWCNTs were present) lead to smaller crystalline domains.

\section{Conclusions}

A crystallization study has been performed with the PLLA/MWCNT system where effects caused by chain extension, functionalization of MWCNTs and the incorporated amount were evaluated. Similar results concerning the overall crystallization rate were found through isothermal and no-isothermal calorimetric methods. In essence, the following features can be emphasized:

The overall crystallization rate decreased for chain extended systems, being MWCNTs involved also in the reaction process. Functionalization of MWCNTs slightly increased the crystallization rate due to an improved compatibility with the polymer matrix.

The content of MWCNT had a higher influence on the crystallization rate, being optimal content close to $0.2 \mathrm{wt} \%$. The nonisothermal crystallization analyses pointed clearly out the negative effect derived from an increase of such content.

Optical microscopy observations revealed a better dispersion of MWCNTs for the indicated $0.2 \mathrm{wt} \%$ and a clear nucleating effect.

Crystallization took place according to a spherulitic growth and a heterogeneous nucleation, being some constrictions detected at high supercooling degrees or at high cooling rates.

Influence of nanoparticles on the crystal growth rate was scarce in comparison with primary nucleation and mainly had a weak influence on the crystallization process governed by secondary nucleation. This feature was also confirmed through calculations of activation energy during non-isothermal crystallization process. Large differences were specifically determined between pristine PLLA and the derived nanocomposites. Furthermore, activation energies were also useful to demonstrate the higher effectivity to enhance crystallization for samples having $0.2 \mathrm{wt} \%$ of nanotubes.

SAXS studies showed that the incorporation of MWCNTs has some influence on the lamellar morphology attained during cold crystallization processes. In any case, the effect was highly dependent on the way as the samples were previously cooled from the melt and specifically on the pre-existence of crystalline domains before starting cold crystallization.

\section{Acknowledgments}

The authors would like to thank Miss Ina Keridou for her kind assistance in evaluating WAXS and SAXS data.

\section{Declaration of Conflicting Interests}

The author(s) declared no potential conflicts of interest with respect to the research, authorship, and/or publication of this article. 


\section{Funding}

The author(s) disclosed receipt of the following financial support for the research, authorship, and/or publication of this article: JP is grateful to support from MINECO and FEDER (MAT2015-69547-R) and the Generalitat de Catalunya (2014SGR188).

\section{ORCID iD}

Omid Yousefzade (D) http://orcid.org/0000-0001-5717-435X

\section{References}

1. Saini P, Arora M and Kumar MNVR. Poly(lactic acid) blends in biomedical applications. Adv Drug Deliv Rev 2016; 107: 47-59.

2. Murariu M and Dubois P. PLA composites: from production to properties. Adv Drug Deliv Rev 2016; 107: 17-46.

3. Arrieta MP, López J, Ferrándiz S, et al. Characterization of PLA-limonene blends for food packaging applications. Polym Test 2013; 32: 760-768.

4. Yousefzade O, Jeddi J, Vazirinasab E, et al. Poly(lactic acid) phase transitions in the presence of nano calcium carbonate: opposing effect of nanofiller on static and dynamic measurements. J Thermoplast Compos Mater 2018; 1. Epub ahead of print https://doi.org/10.1177/ 0892705718759386.

5. Krikorian V and Pochan DJ. Unusual crystallization behavior of organoclay reinforced poly(L-lactic acid) nanocomposites. Macromolecules 2004; 37: 6480-6491.

6. Brzeziński M, Bogusławska $\mathrm{M}$, Ilčíková $\mathrm{M}$, et al. Unusual thermal properties of polylactides and polylactide stereocomplexes containing polylactide-functionalized multi-walled carbon nanotubes. Macromolecules 2012; 45: 8714-8721.

7. Liu C, Jia Y and He A. Preparation of higher molecular weight poly (L-lactic acid) by chain extension. Int J Polym Sci 2013; 2013: 6.

8. Liu Y, Wang L, He Y, et al. Non-isothermal crystallization kinetics of poly(L-lactide). Polym Int 2010; 59: 1616-1621.

9. Kawai T, Rahman N, Matsuba G, et al. Crystallization and melting behavior of poly (L-lactic acid). Macromolecules 2007; 40: 9463-9469.

10. Bouapao L, Tsuji H, Tashiro K, et al. Crystallization, spherulite growth, and structure of blends of crystalline and amorphous poly(lactide)s. Polymer 2009; 50: 4007-4017.

11. Frone AN, Berlioz S, Chailan JF, et al. Morphology and thermal properties of PLA-cellulose nanofibers composites. Carbohydr Polym 2013; 91: 377-384.

12. Miyata $\mathrm{T}$ and Masuko T. Crystallization behaviour of poly(L-lactide). Polymer 1998; 39: 5515-5521.

13. Nam JY, Sinha Ray S and Okamoto M. Crystallization behavior and morphology of biodegradable polylactide/ layered silicate nanocomposite. Macromolecules 2003; 36: 7126-7131.

14. Lotz B, Li G, Chen X, et al. Crystal polymorphism of polylactides and poly(Pro-alt-CO): the metastable beta and gamma phases. Formation of homochiral PLLA phases in the PLLA/PDLA blends. Polymer 2017; 115: 204-210.

15. Zhang J, Tashiro K, Tsuji H, et al. Disorder-to-order phase transition and multiple melting behavior of poly(L-lactide) investigated by simultaneous measurements of WAXD and DSC. Macromolecules 2008; 41: 1352-1357.

16. Yousefzade O, Hemmati F, Garmabi H, et al. Thermal behavior and electrical conductivity of ethylene vinyl acetate copolymer/expanded graphite nanocomposites: effects of nanofiller size and loading. J Vinyl Addit Technol 2016; 22: 51-60.

17. Martínez-Palau M, Franco L and Puiggalí J. Isothermal crystallization of poly(glycolic acid-alt-6-hydroxyhexanoic acid) studied by DSC and real time synchrotron SAXS/WAXD. Polymer 2007; 48: 6018-6028.

18. Papageorgiou GZ, Achilias DS, Nanaki S, et al. PLA nanocomposites: effect of filler type on non-isothermal crystallization. Thermochim Acta 2010; 511: 129-139.

19. Li H and Huneault MA. Effect of nucleation and plasticization on the crystallization of poly(lactic acid). Polymer 2007; 48: 6855-6866.

20. Pilla S, Kim SG, Auer GK, et al. Microcellular extrusionfoaming of polylactide with chain-extender. Polym Eng Sci 2009; 49: 1653-1660.

21. Sungsanit K, Kao N, Bhattacharya SN, et al. Physical and rheological properties of plasticized linear and branched PLA. Korea Aust Rheol J 2010; 22: 187-195.

22. Nofar M, Zhu W, Park CB, et al. Crystallization kinetics of linear and long-chain-branched polylactide. Ind Eng Chem Res 2011; 50: 13789-13798.

23. Xu Z, Niu Y, Wang Z, et al. Enhanced nucleation rate of polylactide in composites assisted by surface acid oxidized carbon nanotubes of different aspect ratios. ACS Appl Mater Interfaces 2011; 3: 3744-3753.

24. Hu X, An H, Li ZM, et al. Origin of carbon nanotubes induced poly(L-lactide) crystallization: surface induced conformational order. Macromolecules 2009; 42: 3215-3218.

25. Chen P-Y, Lian HY, Shih YF, et al. Preparation, characterization and crystallization kinetics of Kenaf fiber/ multi-walled carbon nanotube/polylactic acid (PLA) green composites. Mater Chem Phys 2017; 196: 249-255.

26. Schawe JEK, Pötschke P and Alig I. Nucleation efficiency of fillers in polymer crystallization studied by fast scanning calorimetry: carbon nanotubes in polypropylene. Polymer 2017; 116: 160-172.

27. Kar GP and Bose S. Nucleation barrier, growth kinetics in ternary polymer blend filled with preferentially distributed carbon nanotubes. Polymer 2017; 128: 229-241.

28. Xiao H, Yang L, Ren X, et al. Kinetics and crystal structure of poly(lactic acid) crystallized nonisothermally: effect of plasticizer and nucleating agent. Polym Compos 2010; 31: 2057-2068.

29. Li Y, Wang Y, Liu L, et al. Crystallization improvement of poly(L-lactide) induced by functionalized multiwalled carbon nanotubes. J Polym Sci Part B Polym Phys 2009; 47: 326-339. 
30. Shieh YT, Liu GL, Twu YK, et al. Effects of carbon nanotubes on dynamic mechanical property, thermal property, and crystal structure of poly(L-lactic acid). J Polym Sci Part B Polym Phys 2010; 48: 145-152.

31. Chen C, He BX, Wang SL, et al. Unexpected observation of highly thermostable transcrystallinity of poly(lactic acid) induced by aligned carbon nanotubes. Eur Polym J 2015; 63: 177-185.

32. Najafi N, Heuzey MC, Carreau PJ, et al. Control of thermal degradation of polylactide (PLA)-clay nanocomposites using chain extenders. Polym Degrad Stabil 2012; 97 : $554-565$.

33. Al-Itry R, Lamnawar K and Maazouz A. Reactive extrusion of PLA, PBAT with a multi-functional epoxide: physico-chemical and rheological properties. Eur Polym $J$ 2014; 58: 90-102.

34. Al-Itry R, Lamnawar K and Maazouz A. Improvement of thermal stability, rheological and mechanical properties of PLA, PBAT and their blends by reactive extrusion with functionalized epoxy. Polym Degrad Stabil 2012; 97 : 1898-1914.

35. Cailloux J, O. Santana O, Franco-Urquiza E, et al. Sheets of branched poly (lactic acid) obtained by one-step reactive extrusion-calendering process: Physical aging and fracture behavior 2014; 49: 4093-4107.

36. Yousefzade O, Garmabi H, Puiggali J, et al. Rigid amorphous phase and constrained polymer chains in poly(L-lactide) nanocomposites with carboxylated carbon nanotubes prepared via reactive melt mixing. Polym Compos 2018; 39: 1280-1293.

37. Datsyuk V, Kalyva M, Papagelis K, et al. Chemical oxidation of multiwalled carbon nanotubes. Carbon 2008; 46: 833-840.

38. Yousefzade O, Garmabi H and Puiggali J. Cooperative rearranging region and dynamical heterogeneity of nanocomposites in poly(L-lactide) and functionalized carbon nanotubes systems. Thermochim Acta 2018; 667: 35-41.

39. Avrami M. Granulation, phase change, and microstructure kinetics of phase change. III. J Cheml Phys 1941; 9: 177-184.

40. Pan P, Kai W, Zhu B, et al. Polymorphous crystallization and multiple melting behavior of poly(L-lactide): molecular weight dependence. Macromolecules 2007; 40: 6898-6905.
41. Park SH, Lee SG and Kim SH. Isothermal crystallization behavior and mechanical properties of polylactide/carbon nanotube nanocomposites. Compos Part A Appl Sci Manuf 2013; 46: 11-18.

42. Jeziorny A. Parameters characterizing the kinetics of the non-isothermal crystallization of poly(ethylene terephthalate) determined by d.s.c. Polymer 1978; 19: 1142-1144.

43. Liu T, Mo Z, Wang S, et al. Nonisothermal melt and cold crystallization kinetics of poly(aryl ether ether ketone ketone). Polym Eng Sci 1997; 37: 568-575.

44. Friedman HL. Kinetics of thermal degradation of charforming plastics from thermogravimetry. Application to a phenolic plastic. J Polym Sci C Polym Symposia 1964; 6: 183-195.

45. Vyazovkin S. Modification of the integral isoconversional method to account for variation in the activation energy. J Comput Chem 2001; 22: 178-183.

46. Vyazovkin S and Dranca I. Isoconversional analysis of combined melt and glass crystallization data. Macromol Chem Phys 2006; 207: 20-25.

47. Papageorgiou GZ, Achilias DS, Bikiaris DN, et al. Crystallization kinetics and nucleation activity of filler in polypropylene/surface-treated $\mathrm{SiO}_{2}$ nanocomposites. Thermochim Acta 2005; 427: 117-128.

48. Hao W, Yang W, Cai H, et al. Non-isothermal crystallization kinetics of polypropylene/silicon nitride nanocomposites. Polym Test 2010; 29: 527-533.

49. Chen HM, Zhang WB, Du XC, et al. Crystallization kinetics and melting behaviors of poly(L-lactide)/graphene oxides composites. Thermochim Acta 2013; 566: 57-70.

50. Santis PD and Kovacs AJ. Molecular conformation of poly(S-lactic acid). Biopolymers 1968; 6: 299-306.

51. Hoogsteen W, Postema AR, Pennings AJ, et al. Crystal structure, conformation and morphology of solutionspun poly(L-lactide) fibers. Macromolecules 1990; 23: 634-642.

52. Strobl GR and Schneider M. Direct evaluation of the electron density correlation function of partially crystalline polymers. J Polym Sci Polym Phys Ed 1980; 18: 1343-1359. 